\title{
Scale and scope economies of distance education in Australian universities
}

\author{
Liang-Cheng Zhang ${ }^{\mathrm{a}}$ and Andrew C. Worthington ${ }^{\mathrm{a}}$
}

${ }^{a}$ Department of Accounting, Finance and Economics, Griffith University, 170 Kessels Rd, Nathan QLD 4111, Australia

Despite compelling qualitative arguments for scale and scope economies in university-level distance education, as distinct from traditional class-based face-to-face instruction, there is little rigorous quantitative evidence in support. In this paper, we explore the scale and scope economies of distance education using a multiplicatively separable cost function and a sample of 37 Australian public universities over the 10-year period from 2003 to 2012. The results suggest strong overall scale and scope economies and product-specific scale economies for distance education. Further, the economies of scope for distance education are increasing with mean output, suggesting an increasing cost benefit of producing distance education in conjunction with traditional class-based face-to-face teaching. This provides an important implication: when allocating places for different modes of attendance or considering further expansion of student numbers, there should be a priority on distance education as a means of achieving significant cost savings.

Corresponding author:

Professor Andrew C. Worthington

Department of Accounting, Finance and Economics

Griffith Business School, Griffith University

170 Kessels Road

NATHAN QLD 4111

$\underline{\text { Australia }}$

Tel: $\quad+61(0) 737354273$

Fax: +61 (0)7 37353719

Email: a.worthington@griffith.edu.au

Acknowledgements:

The authors would like to thank two anonymous reviewers, the editor (Vincent Meek), and Christopher O’Donnell as discussant and other participants at the 2014 Asia-Pacific Productivity Conference held in Brisbane for helpful comments and suggestions on an earlier version of this paper. 


\section{Introduction}

Outside traditional class-based face-to-face teaching, distance education (also known as distributed learning, e-learning, or online learning as distinct from hybrid or blended learning involving some physical campus presence other than for assessment) has thrived for decades. Distance education distinguishes itself from traditional modes in not just the manner of transmission, but also the potential students it targets. In the early stages of distance education, these distance programs were mainly broadcast using closed-circuit television and written materials. With the widespread use of computers and the internet, distance education now takes more varied presentation forms, including video instruction and online learning to help students study without the limit of time and location.

These so-called online technologies further enrich learning environments by providing additional multimedia resources and help improve the communication and interaction between instructors and students (Calvert 2005). Distance education also enables higher education institutions to extend their products to distant markets previously beyond their reach. As a result, governments, as principal funders if not providers of tertiary education in many countries, consider distance education as an effective tool to improve educational access and equity for individuals previously excluded from education after secondary school (Rumble 2004; Calvert 2005; Li, Zhou, and Fan 2014). Yet another common interest shared by educational institutions and governments alike are the potential cost savings associated with providing distance education over more traditional delivery modes.

One possible source of cost savings is economies of scale, such that average costs per student fall as fixed costs spread over increasing numbers of students. In distance education, these fixed costs mainly consist of the design and delivery of courses in that a distance 
education instructor usually spends more time designing and producing instruction than does a face-to-face instructor. Once the courses are prepared, the delivery costs of distance education arise from the maintenance of large files and multiple simultaneous users and typically require considerable bandwidth. Together, these factors imply distance education courses and programs have a relatively high share of fixed costs and require sufficient students to achieve economies of scale with delivery. Nonetheless, with the advancement of technology, one advantage of distance education is that it has a much higher theoretical upper limit to enrolment than face-to-face teaching, leading to additional potential scale economies for distance education that in most cases face-to-face teaching simply cannot attain.

The other main economies in distance education arise from economies of scope: cost savings resulting from the joint production of distance education and other education outputs. In the past, a single higher education institution (an open university) sometimes dominated the provision of distance education in a country. There is therefore little allowance for scope economies in this single-output context. However, over the last three decades, more and more traditional classroom-based higher education providers have moved to provide distance education for students choosing not to attend on campus (King 2012). These dual- or mixed-mode institutions provide both on-campus and distance (or off-campus) education to match the needs of flexible learning styles.

Fortunately, for dual-mode institutions, there are potential scope economies between face-to-face teaching and distance delivery (Morris 2008) in that the same academic staff can teach both types of courses through allocating their time and energy, along with the sharing and adaptation of course materials across other courses. Providing distance education also requires more information technology and qualified faculty to support teaching and research activities. These will in turn reduce the costs of producing on-campus teaching and research (Li and Chen 2012). Therefore, providing distance education could assist dual-mode 
institutions to achieve scope economies by better spreading the costs of expensive infrastructure and the employees needed for internet delivery over all students across different modes of attendance.

However, the precise nature of the scale and scope economies in distance education is far from resolved (Cohn and Cooper 2004; Morris 2008). Most importantly, maintaining a comparable teaching quality with on-campus teaching implies student-staff ratios still drive the variable costs of distance education: the larger the class, the greater the additional lecturer time and the number of tutors required. Therefore, the amount of any cost savings still depend on variable costs, which will vary with the number of students, including additional lecturer time for personalised support and the number of tutors hired. The cost of labour-intensive student support could also impair cost economies gained in other areas (Laurillard 2007). For example, the higher dropout rates experienced in distance education (Sweet 1986) are a factor that may serve to erode its cost advantage with increased student turnover through dissatisfaction. Therefore, when the number of students is increasing, the unit cost of distance education graduates could increase because more distance education students drop out. Unfortunately, these factors are difficult to identify as most existing studies of the economies in distance education employ a simple activity-based costing approach (Rumble 1992, 1997) or rely on limited samples of single-mode institutions (Wagner 1972, 1977; Muta and Sakamoto 1989). Of the existing literature, our analysis most relates to Li and Chen’s (2012) seminal exploration of scope economies in distance education.

However, we further contribute to the literature by investigating the average incremental costs and the multiple output scale economies of distance education in dual-mode higher education institutions. Specifically, we first test whether it is possible to lower unit costs by increasing the number of distance education students. Put differently, what is the nature of the economies of scale in distance education? We then examine whether traditional higher 
education institutions should additionally provide distance education to traditional on-campus teaching modes to save costs. That is, are there economies of scope between face-to-face teaching and distance education?

The remainder of the paper is structured as follows. Section 2 details our method for estimating scale and scope economies. Section 3 defines our dataset and the variable specification. Section 4 discusses the results. The final section provides our concluding remarks.

\section{Scale and scope economies in higher education}

To estimate the cost economies, we first consider a higher education institution as a multiproduct firm (Cohn and Cooper 2004). Suppose an institution produces $n$ types of product whose quantities are contained in the vector $\boldsymbol{y}=\left(y_{1}, \ldots, y_{n}\right)$ with $m$ types of inputs whose quantities are $\boldsymbol{x}=\left(x_{1}, \ldots, x_{m}\right)$ given a vector of input prices, $\boldsymbol{w}=\left(w_{1}, \ldots, w_{m}\right)$, a multi-output cost function can then be specified as:

$C(\boldsymbol{y}, \boldsymbol{w})=\min _{x \geq 0}\{\boldsymbol{w} \cdot \boldsymbol{x} \mid(\boldsymbol{x}, \boldsymbol{y}) \in T\}$

Here, the multi-output cost function, $C(\boldsymbol{y}, \boldsymbol{w})$, describes total cost as a function of the output quantities $(\boldsymbol{y})$ and the input prices $(\boldsymbol{w})$. The right-hand side of (1) provides that the condition of this cost function should be the minimum total cost combination of producing $n$ types of output $(\boldsymbol{y})$ given the input prices $(\boldsymbol{w})$ with the multi-output technology set $(T) . \boldsymbol{w} \cdot \boldsymbol{x}$ is the inner product $\left(\sum_{i}^{m} w_{i} x_{i}\right)$ and is aggregated into observed total cost.

In this analysis, we focus on four types of cost economies using (1). These estimates can potentially assist higher education institutions decide their optimal output allocations in terms of the output quantities and mix. The first type of cost economies is the ray economies of 
scale (SRAY). Using the cost function in (1), this is expressed as:

$$
\mathrm{SRAY}=\frac{C(\boldsymbol{y}, \boldsymbol{w})}{\sum_{i=1}^{n} y_{i} \frac{\partial C}{\partial y_{i}}}
$$

where $C(\boldsymbol{y}, \boldsymbol{w})$ is the total cost of producing all the outputs given the different output values $\left(y_{1}, \ldots, y_{n}\right)$ and the mean prices, such that $\partial C / \partial y_{i}$ is the marginal cost of producing product $y_{i}$. This indicator calculates the effect of a simultaneous and proportional increase of all output scale along a ray in output space while holding the composition of each institution's outputs constant. This calculation involves the addition of different types of output, where these additions are a composite commodity or an output bundle that allow the scale to change in a fixed proportion. If there are ray economies of scale, it means that ray average cost (RAC) is declining with the level of output because average cost is being pulled down by producing one more unit.

The second type of estimate, product-specific economies of scale, allows only a single type of output to vary at a time while holding all other outputs constant. Using the cost function in (1) again, we express this as:

$$
\mathrm{Sy}_{i}=\frac{C(\boldsymbol{y}, \boldsymbol{w})-C\left(\mathrm{y}_{-i}\right)}{y_{i} * \frac{\partial C}{\partial y_{i}}}, \text { for } i=1, \ldots, n
$$

where $\mathrm{C}\left(\mathrm{y}_{-i}\right)$ is the cost of producing all the outputs except the $i$-th type of output, and, therefore, $C(\boldsymbol{y}, \boldsymbol{w})-C\left(\mathrm{y}_{-i}\right)$ is the incremental cost due to producing the $i$-th type of output. This shows the degree a multiproduct institution's operation could vary by changing the output of one product while holding the quantities of other products constant (Cohn and Cooper 2004). Economies (diseconomies) of scale exist when this value is greater (less) than unity.

These estimates can help institutions decide how large a scale at which they should 
operate, while the following two estimates further indicate the scope of operations. Global economies of scope (GSE) are the percentage of cost savings from joint production relative to fully integrated costs or the percentage increase in costs from specialized production:

$\mathrm{GSE}=\frac{\sum_{i=1}^{n} C\left(y_{\mathrm{i}}\right)-C(\boldsymbol{y}, \boldsymbol{w})}{C(\boldsymbol{y}, \boldsymbol{w})}$

where $\sum_{i=1}^{n} C\left(y_{\mathrm{i}}\right)$ is the cost of producing product $i$ in $n$ separate or specialised institutions, and $C(\boldsymbol{y}, \boldsymbol{w})$ is the costs of producing all $n$ products jointly within an institution.

When an institution enjoys cost savings from the joint production of various products, GSE will be greater than zero. It also implies that the cost of producing different types of products is less than the cost of producing them separately. When an institution does not experience economies of scope, it would be logical for a multiproduct institution to be broken up into several specialized institutions to save costs. Similar to scale economies, the concept of scope economies can also apply to product-specific measures.

The final estimate, product-specific scope economies, is the percentage of cost savings from the joint production of a particular type of output with other types of outputs:

$$
\operatorname{PSE} y_{\mathrm{i}}=\frac{\left[C\left(y_{\mathrm{i}}\right)+C\left(y_{\mathrm{n}-\mathrm{i}}\right)\right]-C(\boldsymbol{y}, \boldsymbol{w})}{C(\boldsymbol{y}, \boldsymbol{w})}, \text { for } i=1, \ldots, n
$$

where $C\left(y_{\mathrm{n}-\mathrm{i}}\right)$ is the cost of producing all products except for product $i$. The presence of product-specific scope economies implies that the cost of producing a specific type of product jointly with other types of products is less than that to produce it separately.

Together, these estimations provide higher education institutions and their stakeholders with knowledge of the current cost structure that underpins provision in the higher education sector, i.e. average cost, marginal cost and the extent of scale and scope economies, as well as the potential efficiency gains from operating at an efficient scale. To date, there are analyses 
of economies of scale and scope in higher education for Australia (Lloyd, Morgan and Williams 1993; Worthington and Higgs 2011), China (Cheng and Wu 2008; Hou, Li and Min 2009; Li and Chen, 2012), Germany (Johnes and Schwarzenberger 2011), Japan (Hashimoto and Cohn 1997; Nemoto and Furumatsu 2014), Taiwan (Fu, Huang and Yang 2011), the UK (Johnes, Johnes and Thanassoulis 2008; Johnes and Johnes 2009), and the US (Sav 2011; Agasisti and Johnes 2015). However, most of these studies focus on the estimation of scale and scope economies in conventional (face-to-face) instruction, somewhat neglecting product differentiation in the form of distance education (Cohn and Cooper 2004).

\section{Data and specification}

We employ a balanced panel dataset comprising 37 Australian public universities over the period 2003-2012 from the Department of Industry, Innovation, Science, Research, and Tertiary Education (DIISRTE). Australian universities provide a good example to investigate these potential cost economies because of their generally successful experiences in distance education (Beldarrain 2006) and their long history of dual-mode provision (Rumble 2004). Unlike internal students attending university on a regular physical basis, students taking distance education in Australia are external students whose learning is through self-paced and structured material delivered by mail or internet. Presently, all public Australian university are dual-mode institutions. Distance education in Australia has not only played an important role of alternative mode of attendance, but also become a rival to on-campus instruction, with the number of external completions increasing 37 percent from 25,360 in 2001 to 34,798 in 2012, with one in every ten graduates graduating through distance education in 2012 (DIISRTE 2013).

The dependent variable is total operating expenditure. We include four outputs and three input prices in the cost function. The outputs $(y)$ consist of on-campus completions $\left(y_{1}\right)$, 
distance completions $\left(y_{2}\right)$, multi-modal completions $\left(y_{3}\right)$, and number of publications $\left(y_{4}\right)$. The three factor prices $(\mathbf{w})$ are the prices of academic labour $\left(w_{1}\right)$, nonacademic labour $\left(w_{2}\right)$, and nonlabour inputs $\left(w_{3}\right)$. We convert all monetary variables (costs and input prices) to their real values $(2003=100)$ using the consumer price index $(\mathrm{CPI})$ from the Australian Bureau of Statistics. We select these variables based on existing studies in the area, but make a number of modifications to fit the primary purpose of our paper.

We select completions over enrolments or credit hours as the teaching outputs mainly because the number of graduates represents the final instructional product in an institution. This indicator also considers a certain quality of instruction, as all students, regardless of their mode of attendance, must complete the same credit hours and achieve the same academic standards to gain a degree. Nonetheless, this indicator does not account for the number of dropout students, who significantly add to university costs. Therefore, we include the attrition rate for each institution using the proportion of students commencing a bachelor's course in year $(t)$ who neither complete nor return in year $(t+1)$. Lastly, an ideal indicator for the price of capital is capital expenditure divided by net assets. As these data are not available, we specify the number of full-time equivalent (FTE) students as a proxy following Worthington and Higgs (2011).

\section{$<$ INSERT TABLE 1 HERE $>$}

Table 1 provides the means, standard deviations, minimums, and maximums for the pooled data. As shown, some institutions have no distance education outputs, which implies a quadratic cost function (QCF) for $C(\boldsymbol{y}, \boldsymbol{w})$ is more appropriate than other multi-product cost functional forms, including the constant elasticity of substitution (CES) and hybrid translog (TL) function. QCF is also a popular functional form for estimating scale and scope economies in higher education, as it also allows zero values for outputs. However, the difficulties of imposing linear homogeneity and concavity in input prices with this function 
have caused some concern with violating basic cost function assumptions. Some studies (Lloyd et al. 1993; Johnes \& Johnes 2009; Johnes and Schwarzenberger 2011; Agasisti and Johnes 2015) bypass these difficulties by assuming constant input prices across higher education institutions, which is generally acceptable given their (usually) highly regulated context. However, the increasing competition among higher education institutions in both factor and product markets has substantially weakened this premise over time.

To allow for zero outputs as well as imposing the usual cost function assumptions, we propose a multiplicatively separable cost function in (6). This form inherits a quadratic output substructure and makes the impositions easier as the substructure is multiplied by input prices in a Cobb-Douglas functional form. Once we impose linear homogeneity in input prices by summing the price coefficients to one, this functional form further conforms to concavity in input prices.

$C(\boldsymbol{y}, \boldsymbol{w})=\left(\alpha_{0}+\sum_{i=1} \alpha_{i} y_{i}+0.5 \sum_{i=1} \alpha_{i i}\left(y_{i}\right)^{2}+\sum_{i, j=1 ; i \neq j} \alpha_{i j} y_{i} y_{j}\right) \prod_{i=1} w_{i}^{\beta_{i}}$

One additional advantage over its linear counterparts is that this nonlinear form should provide reliable predictions for the value of output variables outside the observed range of the data. This is extremely advantageous when estimating scope economies as we rarely observe zero output in all output variables. An additional benefit is that we can add cost shifters that account for differing operating environments. In order to maintain the cost function assumption, these cost shifters should be in an exponential form. In this way, the sign of the coefficients will not affect the assumption of increasing factor prices.

For a linear model, researchers may use either fixed or random effects to control for any heterogeneity that can arise in panel data. However, there is no accepted procedure for a nonlinear regression model like in our analysis. Categorical indicators for individual traits 
could serve this same purpose. In this regard, an interesting feature of Australian universities is that even though they receive public funding primarily from the Commonwealth (federal) government, they operate under state or territory legislation and therefore they are constrained by state laws. Universities also seek alliances and cooperation with each other, such that institutions often share common traits with institutions in the same state and alliance group. Therefore, we include dummy variables for each of eight regions (states and territories) and four alliance groups to control for heterogeneity. The eight Australian regions specified are New South Wales, Victoria, Queensland, Western Australia, South Australia, the Australian Capital Territory, Tasmania, and the Northern Territory. The four alliance groups comprise the Australian Technology Network, the Group of Eight, the Innovative Research Universities, and the Regional Universities Network. See Garrett-Jones and Turpin (2012) for details.

We use a regression model to link the actual total costs, $c$, with our assumed cost function (6) by involving a multiplicative error which is normal and homoscedastic, that is $\varepsilon \sim N\left(0, \sigma^{2}\right)$.

$c=C(\boldsymbol{y}, \boldsymbol{w}) \cdot \exp \left(\sum_{i}^{13} \delta_{i} Z_{i}\right) \cdot \exp (\varepsilon)=C(\boldsymbol{y}, \boldsymbol{w}, \boldsymbol{Z} ; \boldsymbol{\beta}) \cdot \exp (\varepsilon)$

Here, exp denotes the base of the natural logarithm. The coefficient vector is $\boldsymbol{\beta}=$ $\left[\alpha_{0}, \alpha_{i}, \alpha_{i i}, \alpha_{i j}, \beta_{i}, \delta_{i}\right] . Z_{i}$ is the institutional characteristics including attrition rates and two categorical indictors for region and alliance group. With some transformations by taking logarithms of both sides, we make (6) linear in the parameters of the input prices.

$\ln (c)=\ln (C(\boldsymbol{y}, \boldsymbol{w}, \boldsymbol{Z} ; \boldsymbol{\beta}))+\varepsilon$ 


$$
\begin{aligned}
& =\ln \left(\alpha_{0}+\sum_{i=1}^{4} \alpha_{i} y_{i}+0.5 \sum_{i=1}^{4} \alpha_{i i}\left(y_{i}\right)^{2}+\sum_{i, j=1 ; i \neq j}^{6} \alpha_{i j} y_{i} y_{j}\right) \\
& +\sum_{i=1}^{3} \beta_{i} \ln \left(w_{i}\right)+\sum_{i}^{13} \delta_{i} Z_{i}+\varepsilon
\end{aligned}
$$

Common least squares can still be used to derive coefficient estimators by minimizing the sum of squares, $\Sigma(\ln (\mathrm{c})-\ln (C(\boldsymbol{y}, \boldsymbol{w}, \boldsymbol{Z} ; \boldsymbol{\beta})))^{2}$. This type of question is minimization subject to linear constraints. In our case, the minimization objective function is subject to a linear constraint (the price coefficients sum to one). We can achieve the linear constraint easily by substituting any one of the three coefficients for input prices back into (6). This means we have to impose a functional relationship between the price coefficients, such that $1=\beta_{1}+$ $\beta_{2}+\beta_{3}$. In our case, we choose $\beta_{1}=1-\beta_{2}-\beta_{3}$ to replace $\beta_{1}$ in (8) to obtain the new equation for input prices, $\ln \left(w_{1}\right)+\beta_{2} \ln \left(w_{2} / w_{1}\right)+\beta_{3} \ln \left(w_{3} / w_{1}\right)$. For estimating $\beta_{1}$, we could follow the same procedure, but select either $\beta_{2}$ or $\beta_{3}$ for the substitutions.

One advantage of this estimation method is that it is easier to impose linear homogeneity in input prices in that we do not have to worry about how the choice of a numeriate price might affect the estimated coefficients, as it is invariant to which one of the three price coefficients we choose to drop. However, as $\ln (C(\boldsymbol{y}, \boldsymbol{w}, \boldsymbol{Z} ; \boldsymbol{\beta}))$ is nonlinear in the coefficients, we employ an iterative procedure with initial values for the estimated coefficients to estimate the coefficients. This technique finds application in Izadi et al. (2002) and Johnes (1997) where they estimate a CES cost function for calculating the scale and scope economies of UK universities.

\section{Results}

Table 2 provides the estimates of the four-output multiplicatively separable cost function. We 
estimate the model both with and without the dropout rate, but the two models deliver similar results in terms of the magnitudes, signs, and significance of the estimated coefficients. The regional and alliance group dummies, except for Victoria and Queensland, are all significant. However, this affects the significance of cost complementarity between on-campus and distance teaching $\left(\alpha_{12}\right)$, for which we observe negative values for the coefficient estimates. This cost advantage usually depends on how an institution produces its distance education courses (Rumble 2004). In practice, the teaching arrangements for these two types of courses in Australia used to be separate, but now all students in either mode of attendance largely share the same resources (Calvert 2005). This suggests our finding of significant cost complementarity is convincing.

Unfortunately, as shown in Table 2, we find no evidence of cost complementarity between distance education and multimodal teaching even when accounting for dropout rates. This could be due because producing multimodal teaching is more costly as it consumes resources from both on-campus and distance education. In addition, the provision of multimodal teaching is usually an alternative attendance mode for only on-campus students, with distance education students unable to consider it because they usually live away from the university. In some ways, multimodal teaching dilutes the resources of distance education. As the positive value of $\alpha_{23}$ suggests, producing both distance and multimodal together could therefore lead to expending more resources because the university may have to pay more to achieve the same teaching quality.

In contrast, the coefficient for $\alpha_{24}$ is also positive though insignificant, implying that an increase in distance education and research together will not lead to any cost reduction. This contradicts the result in $\mathrm{Li}$ and Chen (2012), who find cost complementarity between distance education and research in Chinese research universities. To explain this, we should consider the Australian context, such that teaching-focused universities provide most of the degrees 
available through distance education. Research-focused universities, like members of the Group of Eight, typically offer only a limited range of education degrees compared with their relatively large number of on-campus degrees. Considering the significant investments required for courses and research outputs, universities choose to devote less to either of the above outputs, because producing both together in equal quantity could lead to higher costs. We believe this is the reason for the lack of cost complementarity.

\section{$<$ INSERT TABLE 2 HERE $>$}

Given the significant and positive sign of the attrition rate, higher student attrition significantly increases costs as expected. As shown in Table 2, the log-likelihood and lower residual standard error indicates that the model including the dropout rate also has better fit, as does a likelihood ratio test $\left(\chi_{1}^{2}=24.63\right)$. Table 3 details the annual average incremental costs (AICs) for the three teaching outputs (on-campus, distance, and multimodal completions) and research output (number of publications) at $100 \%$ and $200 \%$ of existing mean output over the sample period. To compare the effects of dropout rates on average costs, we calculate all estimates using both the cost functions in Table 2. Our findings show that all three average incremental costs for teaching outputs decline with output regardless of student attrition. However, the AICs for external completions decrease faster than for internal completions. External completions are also the least costly, which is consistent with the findings of previous studies (Wagner 1972, 1977; Rumble 1992).

\section{$<$ INSERT TABLE 3 HERE $>$}

We further find that multimodal completions are the most costly mode at an average cost of $\$ 38,880$, while internal completions are slightly cheaper at around $\$ 37,573$. However, including dropouts helps reduce average costs for distance-related teaching outputs. This especially affects the average cost for distance education. At $100 \%$ of mean output, we can 
decrease unit costs by $27.57 \%$ once we include the dropout rate. As the number of distance education graduates increases, this effect also increases, such that there is an almost $75 \%$ reduction in the average costs of distance education at $200 \%$ of mean output. For multimodal education, this effect disappears once the output scale increases to $200 \%$ of mean output.

We consider that the results for the models with and without dropouts provide some useful ancillary findings. As shown in Table 3, including dropouts in the specification adds marginally to the average cost of internal completions (about $\$ 1,847$ per year per completion). This suggests that dropouts actually lower the average cost per internal completion. We suggest this may be because Australian universities typically overenroll to ensure maximum government revenue and the loss of potential revenue from under enrolment, and that dropouts enable them to become more inefficient by eliminating the costs associated with these excess students. Possibilities include combining classes, closing courses, streamlining offerings, etc. In contrast, including dropouts significantly increases the average cost of external completions by about $\$ 9,385$ per year per completion. This suggests that dropouts are a relatively more significant driver of the average cost of distance learning, especially in that we only analyse costs and ignore the foregone revenue.

The estimates of the scale and scope economies may also vary with output expansion and contraction so we extend the mean output range to 50-200\%. Tables 4 and 5 summarize these estimates and indicate whether the Australian university sector as a whole is experiencing economies of scale (greater than one) or economies of scope (greater than zero). Surprisingly, even though including student dropouts dramatically affects the estimates of the AICs, the results show strong similarity in the scale economies. As shown in Table 4, ray scale economies (SRAY) exist up to $200 \%$ of mean output, implying improvements in cost efficiency by expanding all outputs up to at least $200 \%$ of current mean output. 
When not all outputs change proportionally, product-specific economies of scale can reveal whether there are economies of scale when only one type of output varies at a time. The three teaching outputs appear to display product-specific scale economies up to $200 \%$ mean output. However, external completions do not have larger potential economies of scale than internal completions until 200\% of mean output. This provides some evidence to support Rumble’s (1987) argument that distance education requires a large and sufficient number of students to produce tangible scale economies.

Economies of scope exist if an estimate is greater than zero. Overall, the estimates of the scope economies in Table 5 support the joint production of all types of output. Global economies of scope (GSE) exist up to $125 \%$ of output mean once we include dropout rates. When not accounting for student attritions, the model produces overestimates: for $100 \%$ of mean output, the estimates indicates that there is a $15.77 \%$ reduction in total costs from offering all outputs, which is slightly higher than the $9.33 \%$ reduction found in Chinese research universities ( $\mathrm{Li}$ and Chen 2012). Once we consider the dropout rate, the cost savings decline to a $7.70 \%$ reduction in total costs for the same mean output level.

\section{$<$ INSERT TABLE 5 HERE $>$}

Estimates of the product-specific scope economies provide clues to the possibilities for separate production. Research is an obvious candidate: scope economies exist up to only $75 \%$ of mean output even without considering dropouts. However, this result indicates some progress in scope economies in this recent sample as Worthington \& Higgs (2011) identified diseconomies of scope for this same output in Australian universities during an earlier period from 1998 to 2006. That is, Australian universities appear to have become better at coordinating the joint production of their several outputs. Scope economies for distance education are even increasing with distance education graduates, representing at least a $10 \%$ reduction in total costs from joint production at $200 \%$ of mean output. These findings suggest 
that significant cost savings result from the new technology and teaching management approaches associated with the delivery of distance education.

\section{Conclusion}

An increasing number of once traditional face-to-face-only teachings institutions now offer distance education courses and programs as a means of reaching potential students. However, we know little about the economies of scale and scope of distance education as one purported benefit of this strategy. This study investigates these economies of distance education in dual-mode institutions using nonlinear regression and a multiplicatively separable cost function for a sample of 37 Australian public universities over the period 2003-2012. Our main findings are as follows.

First, the unit costs for distance education are significantly lower than for conventional teaching modes. However, the economies of scale for on-campus education are generally larger than for distance and multi-modal education unless we include student dropouts and increase the number of students to $200 \%$ of its current mean level. Higher degree student attrition in distance education is a contentious issue in the sector (Roberts 1984; Kember 1989; Danaher, Bowser and Somasundaram 2008; Willging and Johnson, 2009; Greenland and Moore 2014). Our results suggest that the costs associated with the less than efficient scale of distance education currently offered by Australian universities in general and the additional costs associated with a high level of student attrition remain the main challenges from a cost perspective.

Second, under the condition that all outputs change proportionally, our findings support joint production of all outputs up to $125 \%$ of current mean output. Once we assume the output change is not proportional, the results of product-specific scope economies for the two distance teaching outputs (distance and multimodal) demonstrated that higher education 
institutions should not deliver distance education separately to traditional on-campus teaching because of the significant cost benefit. As an ancillary finding, the diseconomies of scope for research indicate the costs of producing research output jointly with the other types of products are more than producing it separately. This indicates that the current teaching and research model adopted for all 37 Australian universities results in significant cost inefficiencies, suggesting that at least some specialized institutions focusing on either teaching or research could be more cost efficient for the institutions themselves, the sector, and the Commonwealth government as the principal funder.

Finally, our findings of ray scale and global scope economies suggest a trade-off between scale and scope economies. With the increase in output scale, only scale economies increase, while the scope economies generally decline. However, it does not necessarily mean that all product-specific scope economies will follow the same pattern. Economies of scope for distance education are actually increasing with mean output. This yields an important implication: when allocating places across different modes of attendance or considering further expansion of student numbers, there should be a priority on distance education as a way to achieve significant cost savings.

\section{References}

Agasisti, T., and G. Johnes. 2015. Efficiency, costs, rankings and heterogeneity: The case of US higher education. Studies in Higher Education 40, no. 1: 60-82.

Beldarrain, Y. 2006. Distance education trends: Integrating new technologies to foster student interaction and collaboration. Distance Education 27, no. 2, 139-153.

Calvert, J. 2005. Distance education at the crossroads. Distance Education 26, no. 2, 227-238.

Cheng, G., and K. Wu. 2008. The internal efficiency in higher education: An analysis based on economies of scope. Frontiers of Education in China 3, no. 1, 79-96.

Cohn, E., and S.T. Cooper. 2004. Multi-product cost functions for universities: economies of scale and scope. In International Handbook on the Economics of Education, eds. G. Johnes and J. Johnes, 579-612. Cheltenham: Edward Elgar.

Danaher, P.A., D. Bowser, and J. Somasundaram. 2008. The student departure puzzle: Do some faculties and 
programs have answers? Higher Education Research \& Development 27, no. 3, 271-280.

Department of Industry, Innovation, Science, Research, and Tertiary Education (DIISRTE). (2013). Student 2012 Full Year: Selected Higher Education Statistics Publication. Canberra: DIISRTE.

Fu, T., C. Huang, and Y. Yang. 2011. Quality and economies of scale in higher education: A semiparametric smooth coefficient estimation. Contemporary Economic Policy 29, no. 1, 138-149.

Garrett-Jones, S., and T. Turpin. 2012. Globalisation and the changing functions of Australian universities. Science Technology \& Society 17, no. 2, 233-274.

Greenland, S. J., and C. Moore. 2014. Patterns of student enrolment and attrition in Australian open access online education: A preliminary case study. Open Praxis 6, no. 1, 45-54.

Hashimoto, K., and E. Cohn. 1997. Economies of scale and scope in Japanese private universities. Education Economics 5, no. 2, 107-115.

Hou, L., F. Li, and W. Min. 2009. Multi-product total cost functions for higher education: The case of Chinese research universities. Economics of Education Review 28, no. 4, 505-511.

Izadi, H., G. Johnes, R.Oskrochi, and R. Crouchley. 2002. Stochastic frontier estimation of a CES cost function: The case of higher education in Britain. Economics of Education Review 21, no. 1, 63-71.

Johnes, G. 1997. Costs and industrial structure in contemporary British higher education. The Economic Journal 107, no. 442, 727-737.

Johnes, G., and J. Johnes. 2009. Higher education institutions’ costs and efficiency: Taking the decomposition a further step. Economics of Education Review 28, no. 1, 107-113.

Johnes, G., J. Johnes, and E. Thanassoulis. 2008. An analysis of costs in institutions of higher education in England. Studies in Higher Education 33, no. 5, 527-549.

Johnes, G., and A. Schwarzenberger. 2011. Differences in cost structure and the evaluation of efficiency: The case of German universities. Education Economics 19, no. 5, 487-499.

Kember, D. 1989. A longitudinal-process model of dropout from distance education. The Journal of Higher Education 60, no. 3, 278-301.

King, B. 2012. Distance education and dual-mode universities: An Australian perspective. Open Learning: The Journal of Open, Distance and e-Learning 27, no. 1, 9-22.

Laurillard, D. 2007. Modelling benefits-oriented costs for technology enhanced learning. Higher Education, 54, no. 1, 21-39.

Li, F., and X. Chen. 2012. Economies of scope in distance education: The case of Chinese research universities. The International Review of Research in Open and Distributed Learning 13, no. 3, 117-131.

Li, F., M. Zhou, and B. Fan. 2014. Can distance education increase educational equality? Evidence from the expansion of Chinese higher education. Studies in Higher Education 39, no. 10, 1811-1822.

Lloyd, P., M. Morgan, and R. Williams. 1993. Amalgamations of universities: Are there economics of scale or scope? Applied Economics 25, no. 8, 1081-1092.

Morris, D. 2008. Economies of scale and scope in e-learning. Studies in Higher Education 33, no. 3, 331-343.

Muta, H., and T. Sakamoto. 1989. The economics of the University of the Air of Japan revisited. Higher Education 18, no. 5, 585-611. 
Nemoto, J., and N. Furumatsu. 2014. Scale and scope economies of Japanese private universities revisited with an input distance function approach. Journal of Productivity Analysis 41, no. 2, 213-226.

Roberts, D. 1984. Ways and means of reducing early student drop-out rates. Distance Education 5, no. 1, 50-71.

Rumble, G. 1987. Why distance education can be cheaper than conventional education. Distance Education 8, no. 1, 72-94.

Rumble, G. 1992. The competitive vulnerability of distance teaching universities. Open Learning: The Journal of Open, Distance and e-Learning 7, no. 2, 31-45.

Rumble, G. 1997. The Costs and Economics of Open and Distance Learning. Stirling, VA: Routledge.

Rumble, G. 2004. Papers and Debates on the Economics and Costs of Distance and Online Learning. Oldenburg: Bibliotheks-und Informationssystem der Universität Oldenburg.

Sav, G.T. 2011. Panel data estimates of public higher education scale and scope economies. Atlantic Economic Journal 39, no. 2, 143-153.

Sweet, R. 1986. Student dropout in distance education: An application of Tinto's model. Distance Education 7, no. 2, 201-213.

Wagner, L. 1972. The economics of the open university. Higher Education 1, no. 2, 159-183.

Wagner, L. 1977. The economics of the open university revisited. Higher Education 6, no. 3, 359-381.

Willging, P.A., and S.D. Johnson. 2009. Factors that influence students' decision to drop out of online courses. Journal of Asynchronous Learning Networks 13, no. 3, 115-127.

Worthington, A.C., and H. Higgs. 2011. Economies of scale and scope in Australian higher education. Higher Education 61, no. 4, 387-414. 
Table 1. Selected variable statistics, 2003-2012

\begin{tabular}{clrrrr}
\hline \multicolumn{1}{c}{ Variable } & \multicolumn{1}{c}{ Description } & \multicolumn{1}{c}{ Mean } & Std. dev. & \multicolumn{1}{c}{ Min. } & Max. \\
\hline \multicolumn{1}{c}{$c$} & Total operating expenditure (\$000s) & $400,671.26$ & $280,775.63$ & $34,355.00$ & $1,327,777.62$ \\
$y_{1}$ & On-campus education completions (n) & $5,302.43$ & $3,454.09$ & 15.00 & $15,848.00$ \\
$y_{2}$ & Distance education completions (n) & 755.72 & $1,022.00$ & 0.00 & $5,621.00$ \\
$y_{3}$ & Multimodal completions (n) & 534.47 & 730.60 & 0.00 & $4,518.00$ \\
$y_{4}$ & Number of publications (n) & $1,222.31$ & $1,086.73$ & 60.76 & $5,118.15$ \\
$w_{1}$ & Price of academic labour (\$000s) & 76.82 & 15.67 & 52.22 & 131.99 \\
$w_{2}$ & Price of nonacademic labour (\$000s) & 56.77 & 13.07 & 38.83 & 121.97 \\
$w_{3}$ & Price of nonlabor (\$000s) & 8.58 & 4.18 & 3.30 & 28.98 \\
$q$ & Attrition rate (\%) & 18.07 & 6.10 & 6.21 & 38.83 \\
\hline
\end{tabular}


Table 2. Cost function estimates

\begin{tabular}{|c|c|c|c|c|c|c|c|c|c|}
\hline & \multicolumn{2}{|c|}{ Without dropouts } & \multicolumn{2}{|c|}{ With dropouts } & & \multicolumn{2}{|c|}{ Without dropouts } & \multicolumn{2}{|c|}{ With dropouts } \\
\hline & Coefficient & t-value & Coefficient & t-value & & Coefficient & t-value & Coefficient & t-value \\
\hline$\alpha_{0}$ & 828.7017 & $7.5793^{* * *}$ & 571.8348 & $5.8687^{* * *}$ & $\delta_{a 1}$ & 0.1585 & $8.4147^{* * *}$ & 0.1855 & $9.7090^{* * *}$ \\
\hline$\alpha_{1}$ & 1.3197 & $11.9745^{* * *}$ & 1.2253 & $12.3062^{* * *}$ & $\delta_{a 2}$ & 0.1890 & $6.2477^{* * *}$ & 0.2019 & $6.8990^{* * *}$ \\
\hline$\alpha_{2}$ & 1.6334 & $8.2173^{* * *}$ & 1.3094 & $7.4218^{* * *}$ & $\delta_{a 3}$ & 0.1485 & $9.2592^{* * *}$ & 0.1465 & $9.4202^{* * *}$ \\
\hline$\alpha_{3}$ & 1.3603 & $6.3475^{* * *}$ & 1.1438 & $6.0197^{* * *}$ & $\delta_{a 4}$ & -0.0899 & $-3.3580^{* * *}$ & -0.0941 & $-3.6329^{* * *}$ \\
\hline$\alpha_{4}$ & 3.7356 & $9.0022^{* * *}$ & 3.7099 & $9.8519^{* * *}$ & $\delta_{r 1}$ & -0.0743 & $-2.3361^{*}$ & -0.0989 & $-3.1727^{* *}$ \\
\hline$\alpha_{11}$ & -0.0001 & $-4.4893^{* * *}$ & -0.0001 & $-5.1178^{* * *}$ & $\delta_{r 2}$ & -0.0179 & -0.5722 & -0.0389 & -1.2735 \\
\hline$\alpha_{22}$ & -0.0002 & $-3.2360^{* * *}$ & -0.0001 & -1.9600 & $\delta_{r 3}$ & 0.0054 & 0.1652 & -0.0501 & -1.4816 \\
\hline$\alpha_{33}$ & -0.0002 & -1.2407 & -0.0001 & -0.5501 & $\delta_{r 4}$ & -0.0763 & $-2.3129^{*}$ & -0.0969 & $-3.0013^{* * *}$ \\
\hline$\alpha_{44}$ & -0.0007 & $-2.5702^{*}$ & -0.0009 & $-3.4413^{* * *}$ & $\delta_{r 5}$ & -0.1463 & $-4.2147^{* * *}$ & -0.1789 & $-5.2153^{* * *}$ \\
\hline$\alpha_{12}$ & -0.0001 & -1.6548 & -0.0001 & $-2.5243^{*}$ & $\delta_{r 6}$ & -0.1961 & $-4.3269^{* * *}$ & -0.2087 & $-4.7593^{* * *}$ \\
\hline$\alpha_{13}$ & -0.0001 & -1.4875 & -0.0001 & -0.9964 & $\delta_{r 7}$ & 0.1417 & $3.4348^{* * *}$ & 0.1134 & $2.8034^{* * *}$ \\
\hline$\alpha_{14}$ & 0.0001 & $1.9740^{*}$ & 0.0002 & $2.9509^{* *}$ & $\delta_{r 8}$ & -0.3115 & $-6.2705^{* * *}$ & -0.3791 & $-7.4747^{* * *}$ \\
\hline$\alpha_{23}$ & 0.0001 & 1.0137 & 0.0001 & 1.4311 & $\delta_{d}$ & & & 0.0087 & $4.8635^{* * *}$ \\
\hline$\alpha_{24}$ & -0.0001 & -0.3401 & 0.0001 & -0.0855 & $R S E$ & 0.0725 & & 0.0701 & \\
\hline$\alpha_{34}$ & 0.0002 & 0.8330 & 0.0001 & 0.5558 & $L L V$ & 461.2200 & & 473.5400 & \\
\hline$\beta_{1}$ & 0.2913 & $6.4227^{* * *}$ & 0.2443 & $5.4381^{* * *}$ & $N$ & 370 & & 370 & \\
\hline$\beta_{2}$ & 0.3445 & $7.5756^{* * *}$ & 0.3739 & $8.4230^{* * *}$ & $\overline{\chi_{1}^{2}}$ & $24.6300^{* * *}$ & & & \\
\hline$\beta_{3}$ & 0.3641 & $17.4825^{* * *}$ & 0.3818 & $18.6251^{* * *}$ & & & & & \\
\hline
\end{tabular}

This table provides pooled estimates for the nonlinear panel regression (8) of $\ln ($ cost) on $\ln ($ independent variables). All coefficients ( $\left.\boldsymbol{\beta}=\left[\alpha_{0}, \alpha_{i}, \alpha_{i i}, \alpha_{i j}, \beta_{i}, \delta_{i}\right]\right)$ are consistent with the notations in (8): $\alpha_{i, i=\{0,1,2,3,4\}}$ are the slope coefficients of the linear terms, $\alpha_{i i, i=\{1,2,3,4\}}$ are the slope coefficients of the quadratic terms, $\alpha_{i j, i=\{1,2,3,4\}, i=\{1,2,3,4\} \text { and } i \neq j}$ are the slope coefficients of the cross-product terms, $\beta_{i, i=\{1,2,3\}}$ are the slope coefficients of the prices, $\delta_{a i, i=\{1,2,3,4\}}$ are the slope coefficients of the dummy variables for alliance group, $\delta_{g i, i=\{1, \ldots, 8\}}$ are the slope coefficients of the dummy variables for region, and $\delta_{d}$ is the slope coefficient of the dropout rate; RSE is residual standard error; LLV is log-likelihood value.

${ }^{*}, * *$, and $^{* * *}$ denote significance at the $0.05,0.01$ and 0.001 level, respectively. 
Table 3. Average incremental cost (\$000s) at mean output

\begin{tabular}{|c|c|c|c|c|c|c|}
\hline \multirow[b]{2}{*}{ Output } & \multicolumn{3}{|c|}{ Mean } & \multicolumn{3}{|c|}{ Mean $\times 2$} \\
\hline & $\begin{array}{l}\text { Without } \\
\text { dropouts }\end{array}$ & $\begin{array}{c}\text { With } \\
\text { dropouts }\end{array}$ & $\%$ change & $\begin{array}{l}\text { Without } \\
\text { dropouts }\end{array}$ & $\begin{array}{c}\text { With } \\
\text { dropouts }\end{array}$ & $\%$ change \\
\hline Internal completions & 35.726 & 37.5732 & $5.17 \%$ & 29.5946 & 32.8182 & $10.89 \%$ \\
\hline External completions & 34.0462 & 24.6609 & $-27.57 \%$ & 16.2851 & 4.0879 & $-74.90 \%$ \\
\hline Multimodal completions & 39.1089 & 38.8802 & $-0.58 \%$ & 35.0743 & 38.247 & $9.05 \%$ \\
\hline Publications & 129.647 & 146.4628 & $12.97 \%$ & 140.812 & 164.76 & $17.01 \%$ \\
\hline
\end{tabular}

Table 4. Scale economies at percentage of current mean output

\begin{tabular}{|c|c|c|c|c|c|}
\hline Level & $\begin{array}{c}\text { Internal } \\
\text { completions }\end{array}$ & $\begin{array}{c}\text { External } \\
\text { completions }\end{array}$ & $\begin{array}{l}\text { Multimodal } \\
\text { completions }\end{array}$ & Publications & SRAY \\
\hline \multicolumn{6}{|c|}{ Excluding dropouts } \\
\hline $50 \%$ & 1.1190 & 1.0315 & 1.0179 & 1.0616 & 1.2033 \\
\hline $75 \%$ & 1.1991 & 1.0539 & 1.0278 & 1.0930 & 1.2027 \\
\hline $100 \%$ & 1.3001 & 1.0835 & 1.0384 & 1.1248 & 1.2286 \\
\hline $125 \%$ & 1.4317 & 1.1245 & 1.0498 & 1.1571 & 1.2701 \\
\hline $150 \%$ & 1.6098 & 1.1853 & 1.0621 & 1.1899 & 1.3251 \\
\hline $175 \%$ & 1.8646 & 1.2844 & 1.0755 & 1.2231 & 1.3945 \\
\hline $200 \%$ & 2.2592 & 1.4751 & 1.0899 & 1.2568 & 1.4814 \\
\hline \multicolumn{6}{|c|}{ Including dropouts } \\
\hline $50 \%$ & 1.1301 & 1.0229 & 1.0080 & 1.0766 & 1.1609 \\
\hline $75 \%$ & 1.2165 & 1.0409 & 1.0121 & 1.1152 & 1.1668 \\
\hline $100 \%$ & 1.3241 & 1.0676 & 1.0163 & 1.1539 & 1.1927 \\
\hline $125 \%$ & 1.4619 & 1.1112 & 1.0205 & 1.1929 & 1.2306 \\
\hline $150 \%$ & 1.6446 & 1.1948 & 1.0248 & 1.2320 & 1.2788 \\
\hline $175 \%$ & 1.8984 & 1.4209 & 1.0292 & 1.2713 & 1.3380 \\
\hline $200 \%$ & 2.2750 & 4.2451 & 1.0336 & 1.3109 & 1.4100 \\
\hline
\end{tabular}


Table 5. Scope economies at percentage of current mean output

\begin{tabular}{cccccc}
\hline Level & $\begin{array}{c}\text { Internal } \\
\text { completions }\end{array}$ & $\begin{array}{c}\text { External } \\
\text { completions }\end{array}$ & $\begin{array}{c}\text { Multimodal } \\
\text { completions }\end{array}$ & Publications & GSE \\
\hline \multicolumn{5}{c}{ Excluding dropouts } \\
\hline $75 \%$ & 0.0624 & 0.1021 & 0.0845 & 0.0272 & 0.2202 \\
$100 \%$ & 0.0371 & 0.0929 & 0.0681 & -0.0122 & 0.1577 \\
$125 \%$ & 0.0180 & 0.0909 & 0.0586 & -0.0464 & 0.1147 \\
$150 \%$ & 0.0019 & 0.0931 & 0.0526 & -0.0787 & 0.0814 \\
$175 \%$ & -0.0129 & 0.0979 & 0.0487 & -0.1108 & 0.0535 \\
$200 \%$ & -0.0271 & 0.1048 & 0.0463 & -0.1436 & 0.0285 \\
\hline $15 \%$ & & Including dropouts & & \\
\hline $50 \%$ & 0.0613 & 0.1031 & 0.0873 & 0.0362 & 0.2312 \\
\hline $75 \%$ & 0.0203 & 0.0867 & 0.0616 & -0.0195 & 0.1361 \\
$100 \%$ & -0.0093 & 0.0833 & 0.0482 & -0.0647 & 0.0770 \\
$125 \%$ & -0.0346 & 0.0857 & 0.0401 & -0.1066 & 0.0324 \\
$150 \%$ & -0.0583 & 0.0914 & 0.0347 & -0.1479 & -0.0054 \\
\hline $175 \%$ & -0.0817 & 0.0994 & 0.0308 & -0.1901 & -0.0399 \\
\hline & -0.1053 & 0.1093 & 0.0280 & -0.2338 & -0.0730 \\
\hline
\end{tabular}

